\title{
Azerbaycan Tiyatrosunda Adil İsgandarov'un Yönetmenlik Anlayışı
}

\author{
Adil Isgandarov's Understanding of Stage Direction at the \\ Azerbaijan Theater
}

Vagif AZIZZOV ${ }^{1}$ (D)

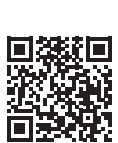

DOI: $10.26650 / C O N S 2021-904372$

'Sanatta Yeterlik Öğrencisi, İstanbul Üniversitesi, Devlet Konservatuvarı, Sahne Sanatları Bölümü, Tiyatro Anasanat Dalı, İstanbul Türkiye

\section{ORCID: V.A. 0000-0001-7836-6406}

\section{Sorumlu yazar/Corresponding author:} Vagif AZiZOV,

İstanbul Üniversitesi, Devlet Konservatuvarı, Sahne Sanatları Bölümü, Tiyatro Anasanat Dalı, İstanbul, Türkiye

E-posta/E-mail: vaqif.aziz92@gmail.com

Başvuru/Submitted: 27.03.2021

ilk Revizyon/Revision Requested: 12.05.202 Son Revizyon/Last Revision Requested: 18.05.2021

Kabul/Accepted: 18.05.2021

Online Yayın/Published Online: 28.05.2021

Atıf/Citation: Azizov, V. 2021. Azerbaycan tiyatrosunda Adil İsgandarov'un yönetmenlik anlayışı. Konservatoryum - Conservatorium, 8(1) 85-102.

https://doi.org/10.26650/CONS2021-904372

\section{öz}

Bu makalede, Azerbaycan Tiyatrosunun tarihsel evrimi içerisinde, Adil İsgandarov'un yönetmen olduğu döneme kadar içinde bulunduğu disiplinsiz çalışma ortamları ele alınarak aynı zamanda Azerbaycan Tiyatro Okulunun da kurucusu olan İsgandarov'un bu bağlamda tiyatro sanatına katkıları ve sanat yaşamının değerlendirilmesi amaçlanmaktadır. Milli Drama Tiyatrosu'nda yarattığı görkemli sahnelemelerine ithafen bir dahi olaraknitelendirilmektedir. Issgandarov, 1936'da Moskova'da eğitimini tamamladıktan ve Bakü'ye döndükten kısa süre sonra baş yönetmenliğe, ardından tiyatronun genel sanat yönetmenliğine terfi etmiştir. Birbiri ardına sahneye koyduğu eserlerle Azerbaycan tiyatrosunu, ülkenin (SSCB'nin) en gelişmiş tiyatroları seviyesine yükseltmiştir. 1938 yılında S. Vurgun'un "Vagif" dramının sahnelenmesi, Azerbaycan edebi ortamında büyük beğeni toplamış ve İsgandarov, Onursal Sanat Çalışanı unvanı ile ödüllendirilmiştir. 1943 yılında ise S. Vurgun'un "Ferhat ve Şirin" oyunu rejisiyle Azerbaycan Cumhuriyeti'nin Halk Sanatçısı unvanına layık görülmüştür. Adil İsgandarov'un, Anvar Mammadkhanlı́nın "Doğunun Sabahı" eserini sahnelerken ortaya koyduğu reji, kariyerinin doruk noktası olarak görülür. Çünkü, bu oyun ile Adil İsgandarov'a SSCB Devlet Ödülü (Stalin Ödülü) verilmiştir. Bunların yanı sıra, A. Korneychuk'un “Polad Qartal" ("Plato Krechet"), M. İbrahimov'un "Hayat", C. Cabbarlı'nın “Aydın" piyesi ve farklı pek çok yazarın eserini başarıyla sahneye koymuştur. Bu makalede, çeşitli kaynaklardan yola çıkılarak yapılan incelemede, Adil İsgandarov'un sadece reji alanında değil bütün olarak Azerbaycan tiyatrosuna yeni bir disiplin getirdiği anlaşılmaktadır.

Anahtar Kelimeler: Azerbaycan Tiyatrosu, Adil İsgandarov, Yönetmenlik

\section{ABSTRACT}

This article aims to evaluate the artistic life of Adil Isgandarov, the founder of the Azerbaijan Theater School, by considering the undisciplined working environments in which Adil İsgandarov was a director within the historical evolution of Azerbaijan Theater. He is described as a genius in reference to his magnificent staging which he created in the National Drama Theater. After completing his education in Moscow and returning to Baku in 1936, Isgandarov was promoted to head director and then general artistic director of the theater. With the plays he staged one after another, he raised the theater of Azerbaijan to the level of one of the most developed theaters 
in the country (USSR) and was rewarded by the government. In addition to these achievements, he successfully staged A. Korneychuk's Polad Qartal (Plato Krechet), M. İbrahimov's Hayat, C. Cabbarlı's Aydın, and many different authors' works. In this article, based on various sources, it is argued that Adil İsgandarov brought a new discipline not only to the field of stage direction but also to the wider context of Azerbaijani theater as a whole.

Keywords: Azerbaijani theater, Adil İsgandarov, Stage director

\section{EXTENDED ABSTRACT}

Adil Rza oglu Isgandarov, director and creator of characteristic screen roles, was born on May 5, 1910, in Ganja and played a major role in the formation of the ensemble of actors of the Academic National Drama Theater (Rahimli, 1996, p.91).

Adil Isgandarov had been interested in theatrical art since the final year of high school and was a member of the drama association in Ganja in his early years. During his vacations, when he was a student in Baku and Moscow, Adil Isgandarov produced Jafar Jabbarli's Od Galini, Sevil, Alexander Shirvanzadeh's Namus, and Vano Mchedashvili’s Qaçaq Kərəm using amateur actors. He played the role of Balash in Sevil, Shakinski in Ogtay Eloglu, and Karam in Qaçaq Kərəm in those performances. He got his first professional education in the director-actor field from 1928 to 1931 at the Baku Technical School of Theater. He played various episodic roles on the National Theater's stages during these years, such as the character Yasovul in M.F. Axundzadeh's play, Haci Gara. After graduation from Baku Technical School of Theater he gained professional experience in Moscow from 1932 to 1936 and graduated from the Lunacharsky State Institute for Theater Arts in 1936. On his return to Baku, he worked at the Azerbaijan State Academic National Drama Theater first as a director, then as chief director from 1936 to 1960. It was no coincidence that this art center was called the "Adil Isgandarov Theater" during these years. Alongside his professional director career, he also continued his work as a pedagogue, such as in 1937 at the Baku Theatre School and afterwards at Azerbaijan State Theatre Institution. He became a professor in 1956.

There are many articles about Adil Isgandarov's personality and creative ability. It is an undeniable fact that Isgandarov's creative personality and art always draw the scholars' attention, and Isgandarov's creative personality is the first thing to come to mind when thinking about the national theater culture of Azerbaijan, especially the art of directing. Many mysterious unanswered questions arose during the study on Isgandarov's personality and art. 
This article aims to shed light on the artistic life of Adil İsgandarov, who was one of the famous artists of Azerbaijani theater art, founder of Azerbaijan Theater Direction School. Isgandarov developed the Azerbaijan National Theatre with the plays he staged one after another, thus, the Azerbaijan National Theatre became one of the most developed theaters in the USSR. After the staging of S. Vurgun's drama Vagif in 1938, Adil Isgandarov was awarded the title of Honorary Art Worker. He was awarded by the government the title of Folk Artist of the Republic of Azerbaijan in 1943 following his direction of S. Vurgun's piece Ferhat ve Shirin. Anvar Mammadkhanli's Morning of the East, which was directed by Isgandarov, is considered the highest point of his total carrier. Because, after the direction of Anvar Mammadkhanli's "Morning Of The East" play Adil İsgandarov and a few colleagues of his team were awarded the USSR State Prize (Stalin Prize) by the USSR government. In addition to these plays, he successfully staged M. İbrahimov's Məhəbbət, C. Cabbarlı's 1905-ci ildə, Dönüş, Sabit Rahman's Xoşbəxtlar, Nişanlı Qlz, Mehdi Hüseyin's Nizami, Cavanşir, Rasul Rza's Vəfa, Mammad Said Ordubadi's Dumanlı Təbriz, Anvar Mammadkhalı's Od İçində, Cabbar Macnunbayov's Yanar Dərə, İliç Buxtası, Samad Vurgun's Xanlar, Ilyas Afandiyev's İşılı Yollar, Bahar Suları, William Shakespeare's Othello, Nazim Hikmat's Türkiyede, Huseyin Javid's Şeyx Sənan, Adil Babayev's Cəfər Cabbarl qəhrəmanları arasında, İslam Safarli’s Ana Ürəyi, and many different authors' plays. Alongside the National Drama Theater, Adil Isgandarov performed at the Opera and Ballet Theatre, the Russian Drama Theatre, the Musical Theater, and the Young Spectators Theater.

Throughout his creative life, Adil Isgandarov made innovations in the theatrical art and culture of Azerbaijan and paved the way for future generations. 


\section{Giriş}

1928-1931 yılları arasında Adil İsgandarov, Bam Tiyatro Okulu'nun yönetmen-oyuncu bölümünde okumuştur. Öğrenci olduğu zamanlarda Azerbaycan Milli Tiyatrosu'nun sahnesine çıkarak küçük rollerde oynamıştır. Tiyatro okulundan mezun olduktan sonra, arkadaşı Cafer Cabbarlı’nın tavsiyesi üzerine yüksek öğrenim için Moskova’ya gitmiştir. Moskova Devlet Tiyatro Sanatları Enstitüsü’nün yönetmenlik bölümünü kazanmıştır. Öğrencilik yıllarında Moskova Bedaye Akademik Drama Tiyatrosu ve Vakhtangov Tiyatrosu'nda ciddi sanat deneylerine iştirak ederek deneyim kazanmıştır (Rəhimli, 1996, s. 62).

Son sinıfta okurken İsgandarov, mezuniyet oyunu hazırlamak üzere Bakü’ye gönderilmiştir. 1935 sonbaharında, Akademi Tiyatrosu'nda Alexander Korneychuk'un "Plato Krechet" eserinin Mustafa Mardanov ve Ulvi Racab tarafından "Çelik Kartal” olarak yeniden adlandırılan bir versiyonu için provalara başlamıştır. Yönetmenin ilk bağımsız çalışması büyük beğeni toplamıştır. Yeniden Moskova’ya dönen Adil İsgandarov, haziran ayında mezun olmuş ve Milli Drama Tiyatrosu'na yönetmen olarak atanmıştır.

Sıradan bir tiyatro yönetmeni olarak işe alınan Adil İsgandarov, 1937'de geçici olarak baş yönetmenlik görevini üstlenmiştir. 1938'de resmen tiyatronun baş yönetmenlik görevine atanmıştır. Daha sonra, genel sanat yönetmeni olarak sanat faaliyetine devam etmiştir. Adil İsgandarov, 1954’te tiyatro müdürlüğü görevini üstlenmiştir. Tiyatroda büyük reformlar gerçekleştiren, güçlü bir ekip kuran, zengin ve renkli bir repertuar oluşturan Adil İsgandarov, 22 Ekim 1960’ta hem tüm görevlerinden hem de genel olarak tiyatrodan beklenmedik bir şekilde uzaklaştırılmıştır. Adil İsgandarov’un, elli yaşında, en verimli ve bilge çağında tiyatrodan dişlanmasıyla, Azerbaycan'ın milli kültürüne ve Akademik $^{1}$ Milli Drama Tiyatrosu'na ciddi bir darbe indirildiği düşünülmektedir. Bu makalede, romantik-gerçekçi tiyatro okulunun kurucusu olan Adil İsgandarov'un, Azerbaycan Milli Drama Tiyatrosu'ndaki sanat yaşamı boyunca titizlikle yaptığı oyun seçimleri, oyunlara estetik yaklaşımı ve yönetmenlik tekniğinin özellikleri incelenmiştir. İsgandarov'a kadar tiyatroda her perde bir yönetmen tarafından yönetildiği için oyunlarda ciddi bir üslup karmaşası yaşanmaktaydı. Bazı dramaturgların ve tiyatrodaki öncü oyun-

1 1919-1991 yılları arasında tiyatronun farklı isimleri olmuş ve hepsinde siyasi-kamusal bir süreçle değiştirilmek zorunda kalınmıştır. 1959 yılına kadar Milli Drama Tiyatrosu adı, 1959 yılında ise, Milli Drama Tiyatrosunun turnelerdeki başarısı, tiyatronun repertuar politikası, romantik ve gerçekçi oyunculuk okullarının oluşumu, yönetmenlik sanatının gelişmesi, SSCB’nin merkezi gazetelerinde büyük beğeni ile yazılmış olması değerlendirilmiş ve ‘Akademik’ unvanı verilmiştir. Bu adın verilmesinde İsgandarov’un istisnai rolü olmuştur. 
cuların oyun yönetmesi, oyunlara müdahalesi tiyatronun gelişmesini yavaşlatmakla beraber yeni sorunlar ortaya çıkarmaktaydı. Bu sorunların başında her sene aynı repertuvarların tekrarlanması, tiyatroya yıllarca yeni oyuncuların kazandırılmaması ve genç yönetmenlere oyun yönetmeleri için şans verilmemesi gösterile bilir. İsgandarov'un baş yönetmenlik görevine tayin olunmasıyla bu sorunlar kısa sürede çözülmüş ve ülkenin tiyatro hayatında yenilikler yaşanmıştır. Bu çalışmanın amacı, Azerbaycan Tiyatrosu'nun gelişiminde katkısı bulunan, tiyatroya yeni oyuncular kazandıran, genç yönetmenlere şans tanıyan, yeni repertuvarlarla turnelerde ilgi gören ve tiyatroya 'Akademik' unvan kazandıran Adil İsgandarov'un tiyatrosuna daha yakından bakmayı hedeflemektir. Bu kapsamda, Adil İsgandarov'un hem Azerbaycan Tiyatrosu'na olan etkisi hem de kendisiyle şekillenen 'İsgandarov Tiyatrosu' kavramı incelenmektedir.

\section{Adil İsgandarov Tiyatrosu}

Uzun yıllar boyunca oyuncu tiyatrosu olarak tanınan, güçlü oyuncularının bireysel becerilerinin yardımıyla çeşitli zorlukların üstesinden gelebilen tiyatro, bir anlamda bireysel sanatçıların konumlarını ve isteklerini hesaba katmak zorunda kalmıştır. Tiyatronun psikolojik ve yaratıcı ortamı bu geçen zaman içerisinde şekillenmiştir. Tiyatronun repertuvar politikası, şu ya da bu oyunun kabulü, bazı güçlü sanatçıların performansına ve zevkine bağlı kılınmıştır. Bu nedenle M. Aliyev, S. Ruhulla, A. Garaybeyli, A. Gurbanov, M. Davudova, S. Haciyeva, F. Qədri, M. Valikhanli, K. Ziya ve diğerlerinin görüşleri elbette gözden kaçırılmamıştır. Ancak yirmi sekiz yaşında görevi devralan genç yönetmen, bu konuda uzlaşmaz bir tavır almış ve adım adım amacına ulaşmışıı. A. İsgandarov ilkeli duruşuyla, bazı durumlarda aldığı sert tedbirlerle, oyuncunun tiyatrodaki yönetiminin sona erdiğini haber veren tavırlarıyla, oyuncunun belirleyici olduğu bir tiyatronun sonunu ilan etmekteydi. O, genel müdürdü ve bu pozisyonun yetkisini ustaca kullanmaktayd. Zira Monastyrysky'e göre (1985, s. 3), "Yönetmenlik bir iş değildir. Aynı zamanda bir sanattır ve çok özel bir sanattır". ${ }^{2}$

Ünlü yönetmen A. Popov'un bir görüşü de oldukça manidardır: "Önünde büyük ve sorumlu görevleri olan bir yönetmenin tiyatroda bir üne sahip olmas1 gerekir" (Popov, 1972, s. 9). A. İsgandarov yıllar içinde bu sanatta emek veren bir profesyonel olarak sadece kendi tiyatrosunda değil, genel olarak milli tiyatro kültüründe en etkili otorite haline gelmiştir.

2 Rusça aslından çevirisi makale yazarı tarafından yapılmıştır. 
O dönemde SSCB'deki hemen hemen her tiyatroda hem tiyatronun kendi iç ortamında hem de basında hararetli tartışmalar yaşanmakta ve tiyatronun içerideki konumlandırmalarını belirleme girişimleri olmaktaydı. Bu skandallı süreçte hem duygularıyla hareket eden yazarlar hem de seçkin aktörler hatta; işlerinin ustaları olan yöneticiler bulunmaktaydı. Basit bir mesele etkisi yaratan bu tartışmaların yaratıcı süreci ciddi şekilde sekteye uğrattığı, topluluk içinde tatminsizliğe yol açtı̆̆ı, yıkıcı sonuçları olduğu ve grupları ana sanatsal hedeflerden uzaklaştırdığı ise aşikardır. Aynı zamanda önde gelen tiyatro figürleri konumlarını ifade ediyor, otoritenin etkisiyle yorulan beyinleri soğutmaya çalışıyorlardı. Bu konuda A. İsgandarov'un ölçülü tutumunun ve özlü görüşünün gözden kaçmadığı belirtilmelidir:

"Son zamanlarda basında ve tiyatroların yaratıcı kadroları arasında tiyatroyu kimin yöneteceğine dair bir tartışma meydana geldi. Tiyatroda ana karakter yönetmen mi, oyuncu mu, oyun yazarı mı ya da müdür mü? Tiyatrodaki ana güç olan topluluk, kolektiftir. Oyun, oyun yazarı, yönetmen ve oyuncu tarafindan yaratılmıştır. Tiyatro sanatının başarısı, tüm tiyatro ekibinin fikir birliğine ve ustalığına bağlıdır”3 (İsgandarov, 1958, s. 6).

$\mathrm{Bu}$ her ne kadar basit bir mesele gibi görünse de hafife alınmamalıdır. O zamanlar, milli tiyatroya davet edilen kadronun farklı kuşaklardan oluşan üyeleri hem önceki yıllarda hem de nispeten son yıllarda birlikte çalışmışlardır. Tiyatrodaki psikolojik ve yaratıcı çevrenin düzenlenmesinde genel sanat yönetmeninin yukarıda ifade edilen konularda olduğu gibi ilkeli bir tutum sergilemesi son derece önemli olarak görülmektedir. Bu fikirlerin merkezinde de yeni bir teatral vizyon ve yeni bir sahne etiği fikri yer almaktadır.

A. İsgandarov tarafindan desteklenen teatral görüş, duygusal patlama faktörüne dayandırılıyordu. İzleyici, tutkuların çatışmasından, ezilenlerin zalimlerin baskısı altında çektiği acılardan, gözyaşlarına ve çığlıklara dayalı tiratlardan ve heyecanlı sahnelerden hoşlanmaktaydı. Bu sebeple, oyuncu güçlü ve yankılanan bir sese, güçlü bir beden anlatımına, izleyiciyle bire bir iletişime sahip olmalıydı.

Prof. R. Bədəlov'a göre (1993, s. 71), Adil İsgandarov oyunlarında, her sanatsal araç (oyuncunun duruşu, tonlaması, sahnedeki yeri) belirli bir şiirsel sözcükle, oyuncunun belirli bir statik duruşu ile tam bir uyum gözetiyordu. Gösterileri epizotlardan oluşmak-

3 Azerice aslından çevirisi makale yazarı tarafından yapılmıştır. 
taydı. Milli kökleriyle bağlantılı olmasına rağmen, doğu tiyatrosunun özelliklerinden etkilenmiş romantik bir sahneleme göze çarpıyordu. Oyunculukta doğu tiyatrosunu izleri görülmekteydi. Ancak tiyatro, repertuar seçiminde arayış içindeydi.

O dönemde dramaturji çalışmaları ne kadar zengin olursa olsun bir bütün olarak milli tiyatro kültürünün estetik taleplerini karşılamıyordu. Artık, yönetmene has estetik güçlere olan ihtiyaç ortaya çıkmaya başlamıştı. Milli dramadan M. F. Akhundov, A. Hagverdiyev, N. Vazirov, Cavid, C. Cabbarlı, yabancı yazarlardan Shakespeare, Moliere, Schiller, Lope de Vega ve diğerlerinin eserleri, sahne sanatlarının ideolojik ve estetik gereksinimlerini karşılasa da oyuncuların ve yönetmenlerin becerilerini artırmak için bol miktarda sanatsal firsat sunan araçların ortaya çıkmasına duyulan ihtiyaç son derece açıktı.

Ancak içinde bulunulan dönemin ideolojik koşullarını ve toplumun tiyatro taleplerini görmezden gelmek doğru bir yaklaşım olmayacaktır. En azından, A. İsgandarov tiyatrosunun yaratıcı doğası ve idari süreci iyice düşünülmelidir. O dönemde Sovyetler baskısı yaratıcılığa ket vurmakta, oyunlar da devletin siparişi üzerine sahnelenmekteydi. Yine de yeterince yaratıcı ve özgür olmayan şartlar altında tiyatro birçok sorunu başarıyla çözmüştür. A. İsgandarov ilk bakışta Stanislavski'nin metodolojisini kesin olarak kabul etmiş ancak; uygulamada zorluklar yaşamıştır. Azerbaycan Milli Drama Tiyatrosu'nda görev yapan M. Mammadov, A. Şarifov, T. Kazımov gibi yönetmenler Stanislavski sistemini benimsememişlerdir. Nitekim tiyatro kuramcıları da Stanislavski sisteminin bir doktrin olmadığ 1 sonucuna varmışlardır. Bu nedenle, onu kazanan veya kaybeden ilan etmek kavramsal olarak yanlış ve hatalı bir akıl yürütme olacaktır. Zira, repertuar oluşturma ve oyuncu çalışmalarında İsgandarov'un hem basında hem de çeşitli toplantılarda yaptı̆̆ konuşmalardan sadece, Stanislavski’ye güvendiği anlaşılmaktadır.

A. İsgandarov, tüm Sovyet teatral süreci bağlamında ortaya çıkan teatral reformların izini sürmekte ve bunları kendi tiyatrosunda uygulamaya çalışmaktaydı. O zaman moda olan ve tüm tiyatrolarda çalışması önemli kabul edilen K. S. Stanislavski’nin sahne eğitimi, A. İsgandarov'un yönetmenlik pedagojisinin de temelini oluşturdu. Hatta oyuncuların ilerici sahne estetiğini öğrenmesinin önemli olduğunu düşündüğünden, Stanislavski'nin mirasını incelemek için oyunun tercümesinden prova sürecine kadar ilgili olan her kesin iştiraki ile devam eden bir çalışma sistemi oluşturmuştur. 12 Mayıs 1951'de Fatma Qədri günlüğüne şunları yazdı: «Bugün, Stanislavski’nin mirasını inceleyen çemberin 
bir oturumuydu. Provaları İsgandarov'la ben yaptırıyorduk. Stanislavski'nin eserlerini Rusça okudum, o da tercüme ediyor ve açıklık getirmeye çalışıyordu. Oyuncular fikirlerini ifade ediyor, çoğu tiyatromuzun hayatından örnekler alıyorlardı. Günde iki saat çalışıorduk” (Qədri, 1983, s. 127).

Buna ek olarak, çeşitli gösteriler hazırlama sürecinde, A. İsgandarov yaratıcı personeli müzeleri, arşivleri, kütüphaneleri ziyaret etmek için organize etmiş, eserde anlatılan dönemi ve olayları incelemenin önemli olduğunu ifade etmiştir. Elbette bunlar, oyuncuların dünya görüşünü genişletmeye, estetik bir düşünme biçimi oluşturmaya hizmet eden adımlardı. "Sanatı bilmenin yanı sıra, uygulanan yaşamın ve tarihi malzemenin özelliklerini bilmenin de önemli olduğuna inanıordu”(İsgandarov, 1972, s. 8).

$\mathrm{Bu}$ yaratıcı gereksinimlerle A. İsgandarov yaratıcı kadronun teatral sanata, bireysel üsluplara, sanat konularına ve genel olarak sahne kültürüne karşı tamamen yeni bir tutumunu gündeme getirdi. Seçimini kesin olarak yapmıştı. Bu nedenle yaratıcı kadroyu estetik hedefe yönlendirmek zor olsa da başka bir yolu yoktu. Bunun üzerine A. İsgandarov başkanlığındaki milli tiyatro, geleneklerden yararlandı ve daha ilerici, yaratıcı sahneler uygulamaya koydu. Zaten tiyatro topluluğunda M. Sanani, İ. Dağıstanlı, A. Alakbarov, H. Gurbanova, B. Şakinskaya, A. Sultanov, A. Cavadov, M. Mardanov, R. Afganlı gibi oyuncular güçlü bir yer almış, M. Mammadov, A. Şarifov, T. Kazımov, A. H. Alakbarov gibi yönetmenler yeni estetik ilkelerde ustalaşmıştı. Bir genel sanat yönetmeni olarak A. İsgandarov bir dizi hedefe ulaşmayı başarmıştır. $\mathrm{O}$ andan itibaren, yeni ve daha karmaşık görevlerle başa çıkmak için başarıları ve pozisyonları pekiştirmek gerekiyordu. Bu sorumluluklar nelerdi?

Her şeyden önce, A. İsgandarov, büyük ideolojik ve estetik görevleri ve oyuncaların bireysel çalışmalarını gözeten yeni bir repertuar hazırlamalıydı. A. İsgandarov, yeni bir teatral estetiğin yaratılması için repertuardan çok yaratıcı kadro ve nesillerin değişimi ile ilgileniyordu. Hali hazırda var olan oyuncuların anlayışıyla istediği reformu gerçekleştiremeyeceğini anladı. Bu nedenle, tiyatroya yeni oyuncuların katılımı A. İsgandarov'un sahne metodolojisinin başlangıcı olarak ele alınabilir.

Azerbaycan sahne sanatlarının o dönemi tartışmalı olduğu kadar renkli de geçmiştir. Bir yandan özü tam olarak anlaşılamayan ancak; doğasında reformist eğilimlerin varlığından şüphe duyulmayan Stanislavski sistemi, tiyatroda ana tartışma konusu oldu. Diğer yandan muhafazakâr bir yapısı olan geleneksel oyunun ilkeleri de kaldı ve her zaman seyirciler arasında büyük ilgi uyandıran performanslar gündemdeki yerini korumayı başardı. 
Tiyatro sanatı fikrinin sanatsal yönünü belirleme misyonunu yerine getiren A. İsgandarov'un, masa başı provalarından genel provaya kadar oyun üzerinde yaptığı çalışmalarda bahsettiği ilkeler Stanislavski'ye atıfta bulunmaktaydı. Dolayısıyla, A. İsgandarov'un imge, çevre, oyunun daha yüksek amacı ve bu amacın sanatsal açılardan gerçekleştirilmesine yönelik bilimsel ve teorik kriterleri bulunuyordu. "Oyuncularla çalışırken, her karakterin sanatsal hücresini öğrenme ve bulma talebinin özel bir estetik anlamı vardı. A. İsgandarov'un daveti üzerine tiyatroya gelen N. Malikova, L. Bedirbeyli, M. Sadigov, M. Dadaşov, A. Rzayev, H. Salayev, A. Agayev, A. Gurbanov, M. Şeykhzamanov ve diğerlerinin bu metodolojinin yaratıcı yönlerinden yararlanmaları da tesadüfi değildir." (İsrafilov, 2001, s. 17).

A. İsgandarov'un teatral estetiği hem yönetmen hem de oyuncu için milli estetik içerikte yüceltilmiştir. Başka bir ifadeyle, oyuncu doğrudan bireyselliğinden hareket eder, izleyicinin yaratıcı imajının algısını etkileme araçlarını korur. Farklı oyuncu maskeleri ile karş1 karşıya kalınan bu gibi durumlarda, maskeler neredeyse geleneksel "dell'Arte" komedilerinin estetiğiyle benzeşir. Aslında millidirler ve belki de bu nedenle kolayca tanınır ve kabul edilirler (Talıbov, 1992, s. 10).

A. İsgandarov, oyuncuların büründükleri karakterden bağımsız olarak tanınabilir olmasını engellemeye çalışmıştır. Bunu, teatral unsurlara dayanan bir abartı sanatıyla elde etmeyi hedeflemiştir. Bu bağlamda bir yandan başkalaşmayı oyunculuğun zorunlu bir koşulu olarak gören A. İsgandarov, öte yandan M. Aliyev, M. Sanani, A. Garaybeyli, R. Afganlı ve diğerlerinin seyirci karşısına oldukları gibi çıkmasına uygun görmüştür.

Çelişkinin basit açıklaması, A. İsgandarov'un tiyatrosunda çalışan bazı aktörlerin toplumda ve izleyicinin gözünde popüler hale gelmesidir. Onları çeşitli dış yollarla gizlemek artık mümkün değildir hatta; anlamsız hale gelmiş̧ir. M. Aliyev veya M. Sanani'nin perde arkasındaki sesi gelince, rolleri ne olursa olsun biliniyorlardı ve oditoryumu alkışlar dolduruyordu. Bu faktörü görmezden gelmek ve onu değiştirmeye çalışmak yanlış bir davranış olurdu. Bu nedenle, A. İsgandarov'un oyuncularla çalışma metodolojisindeki bu çözümü amacına ulaşmıştır. Diğer önemli bir nokta da A. İsgandarov’un, oyuncunun hiyerarşisi ilkesine, rol paylaşımında, oyuncularla çalışma sürecinde, tiyatroda etik geleneğinde ve sahne diziliminde değer vermesidir. Prof. R. Bədəlov'a göre (1993, s.27), "Adil İsgandarov'un tiyatrosunda, tiyatronun iç ilişkileri muhtemelen sahnenin ölçeklerine yansıyordu ve oyuncular hiyerarşisi hayattan sahneye geçiyordu". 
A. İsgandarov tiyatro idaresinden sorumlu olduğu yıllarda tiyatro çalışmalarının organizasyonu ve yeni yönetmenlerin katılımıyla, "Bahar Suları", "Doğu Sabahı", "Othello"nun sahnelenmesi ve Azerbaycan tarihindeki diğer milli sahne sanatları ile ilgilenmiştir. Çalışmaları özel araştırma gerektiren A. Şarifov, M. Mammadov, T. Kazımov, Ş. Badalbeyli, A. H. Alakbarov gibi yönetmenlerin faaliyetleri, Milli Drama Tiyatrosu sahnesinde A. İsgandarov'un kontrol ve iyiliksever tavrıyla bağlantılı bir şekilde ele alınmalıdır. Zira bu olağandışı bir şey olmayıp, o dönemin şartları çerçevesinde mutlak bir otorite olan A. İsgandarov'un onayı olmadan milli tiyatro sahnesinde bağımsız bir yapı vermek, tiyatro hayatında bir yer edinmek mümkün değildir. Bu nedenle, daha sonra, milli yönetmenlik sanatının taşıyıcıları ve temsilcileri olan sanatçıların çoğu, A. İsgandarov'un sahne estetiğinin ve ideolojik üstünlüğünün etkisinde kalmıştır. Sonraki dönemde yönetmenlik sanatının, tiyatronun anlatım araçlarını sınırlı bir şekilde kullandığı, sahne tekniğinden başlayarak sanatsal üslup ilkelerini geliştirmeye dahi çalışmadığı görülmüştür. Milli yönetmenlik sanatının, tiyatronun şiirsel potansiyelini bilinçli olarak gölgede bırakma eğilimi ise elbette talihsiz bir yaklaşımdır. Bazı yıllarda Milli Drama Tiyatrosu sahnesinde yorumlama ve sanatsal çözüm ilkelerinde, tiyatronun anlatım araçlarının yararlı ve etkili kullanımında ve şiirsel somutlaşmada ciddi eksiklikler görülmüştür. Bazı yönetmenler profesyonellikten uzak kalmış, basit anlatım araçlarına, hazır şemalara bağımlı bir duruş sergilemiş bu nedenle; sanatsal yaratıcılıktan yoksun oldukları gözlenmiştir (İsrafilov, 2001, s. 77).

Dramatik çalışması, bazı durumlarda düz yazı metinlerin sahnelemesinde etkili olmaktaydı. Fakat yaratıcı kadronun, özellikle de oyuncuların performans becerileri bazen bu duruma yardımcı olmamış, yönetmenin ne istediği ve hangi sanatsal hedefe ulaşmak istediği de netleşmemiştir. Bu tür sahne çalışmalarına örnek olarak S. Turabov'un "Fakhraddin Trajedisi” (1941), A. H. Alakbarov’un “Amerika’nın Sesi” (1950), Ş. Badalbeyli’nin “Aşnalar” (1945), A. Şarifov’un «İpek Desenleri» (1952) rejileri gösterilebilir. Yönetmenin «canlı, zıt bir yaratıcı süreçten yoksun» (Olizadə, 1998, s. 28) eleştirisine katılmamak zor olmakla birlikte, unutulmamalıdır ki A. H. Alakbarov, S. Turabov ve A. Şarifov’un yönetmenlik yaratıcılığında görülen eksiklikler A. İsgandarov’un çalışmalarında gözlemlenmemiştir (İsrafilov, 2001, s. 78).

Elbette, bu Adil İsgandarov'un yapıtlarında hiçbir kusur olmadığı anlamına gelmez. Ancak Adil İsgandarov'un çalışmasında, repertuvarın inşasında, yazarlarla yapılan çalışmalarda, doğrudan performans için hazırladığı eserlerin somutlaşmasında, kural olarak, bir 
sanat disiplini, estetik bir temizlik olduğu yadsınamaz. Adil İsgandarov'un diğer yönetmenlerle ilişkisi de kesin olarak yorumlanamaz. Zira ilerleyen yıllar içerisinde tiyatronun karşı karşıya kaldığı sorunlar ve değişen şartlar, yaratıcı bir kişilik ve idealleri olan bir yönetmen olarak Adil İsgandarov'un kendisini de değiştirmiş ve geliştirmiş̧tir. İsgandarov'un sahne yaratımı ve estetik dünya görüşü konusundaki tutumu olgunlaşıyordu. $\mathrm{Bu}$ nedenle hem ülkedeki tiyatro anlayışına bakışı hem de bireysel yaratıcılara ve bireysel figürlere karşı tutumu farklılık göstermekteydi. Örneğin, Alasgar Şarifov'a, Aliheydar Alakbarov'a, Şamsi Badalbeyli'ye, Saftar Turabov'a tavrı, Mehdi Mammadov'a, Maharram Haşimov'a ve Tofig Kazımov'a olan tutumlarından farklıydı. Aslında bu durum doğal karşılanabilir. Çünkü bu sanatçılar, yaratıcıllk potansiyeli ve üslup özellikleri açısından birbirlerinden farklıdırlar. Tiyatronun genel sanat yönetmeni Adil İsgandarov, kelimenin tam anlamıyla burada görev alan yönetmenlerin çalışmalarına öncülük etmiştir.

Yukarıda adı geçen yönetmenler, tiyatroya dair doğrudan sergilediği tutumu açısından Adil İsgandarov ile daha yakından ilgileniyorlardı. Bununla birlikte genel müdür tarafından belirlenen tüm gereksinimler de öncelikle yaratıcı özellikler barındırıyordu.

Adil İsgandarov Azerbaycan milli tiyatrosunu nasıl gördüyse ya da görmek istediyse, bu kendisi için bir yaratıcılık meselesi, Azerbaycan için ise bir tarihi estetik meseledir. İsgandarov hayatını, tüm becerilerini ve çabalarını, yaratıcı gücünü bu işe adamıştır. Adil İsgandarov'un çalışmalarını farklı yönlere bölmekle, tüm yaratıcı gücünün ve becerilerinin ayırdına varılabilir. Bu yönler nelerdir?

Bu durumda, her şeyden önce, muhtemelen Adil İsgandarov'un tiyatro çalışmasının organizasyonuna değinmek gerekir. $\mathrm{O}$ dönemin karmaşık idari engellerinden bahsedilmiştir. Mesele şu ki, tiyatro organizasyonu alanındaki karmaşık durumu sadece idari engeller ve mali zorluklar şeklinde kabul etmek doğru olmayacaktır. Çünkü bu süreç hem idari ve ekonomik zorluklarla hem de yaratıcı zorluklarla doluydu ve bu durum yönetmen için eşit bir sorunsalı bünyesinde barındırıyordu. Adil İsgandarov bahsedilen idari ve mali sorunları çok kısa sürede çözmeyi başarabilmiştir. Hiç şüphe yok ki, bu sadece milli tiyatronun gelişimindeki ilk ve büyük zafer değil, aynı zamanda gelecekte daha büyük çalışmaların başlangıcı olmuştur.

Adil İsgandarov'un muhtemelen daha büyük olarak ifade edilebilecek diğer bir özelliği, yukarıda da belirtildiği gibi, modern sahne sanatlarının yaratıcı yaşamı için son derece önemli olan milli bir drama yaratmak için yeni yazarları Azerbaycan tiyatrosuna çekebil- 
miş olmasıdır. Bu sayede Azerbaycan tiyatro tarihinin milli bir dramasını yaratma süreci gerçekleşmiştir. Ama daha da önemlisi, tiyatro sürecine dâhil olan yazarların tiyatronun yazarları olması ve tiyatro sanatına farklı, güçlü sanat eserleri vererek büyük bir sahne repertuvarı olan milli tiyatro sorununu çözmeyi başarabilmiş olmalarıdır. Bahsedilen olguların kolay ve çok hızlı gerçekleşmediği ise doğru bir yorumdur. İlk dönemde bu yazarların yaratıcılığı sadece tiyatro sanatı ile bağlantılı olarak ele alınmalıdır. Yaşayan bir sanat alanı olan tiyatro için geçirilen bütün bu aşamalar şüphesiz bedelsiz ve acısız olmamıştır. Bu minvalde bir bütün olarak tiyatro sanatının önemli bir özelliği de dikkate alınmalıdır. Önemli olan nokta, güçlü bir şair ya da güçlü bir yazarın tiyatro için bir eser üzerinde çalışırken başarısız olabileceği ve edebiyata büyük sanatsal katkılarda bulunan bir sanatçının da tiyatro için oyun yazan bir yazar kılığında görülebileceğidir. Bu yaklaşım oyun yazarı, yönetmenin himayesinden mahrum bırakıldığında ortaya çıkar ve yaratıcı bir iş birliği gerçekleşemez.

Adil İsgandarov'un yaratıcı yolunu izleyerek, bu alandaki başarılı çalışmaların meyveleri açıkça görülmektedir. Tiyatroya önde gelen bir şair olarak giren Samad Vurgun, "Vagif" ten sonra birbiri ardına başka oyunlar da ortaya koyarak milli tiyatronun şiirsel dramaturji geleneğini zenginleştiren oyun yazarlarından biri olmuştur. Aynı şey Mirza İbrahimov, Anvar Memmedkhanlı, İlyas Efendiyev, Sabit Rahman için de söylenebilir. Komedi türünde Sabit Rahman, Azerbaycan milli tiyatrosunun önemli komedi yazarlarından biri olmuştur. İlyas Efendiyev'e gelince, bu ünlü yazarın dramatik eseri, repertuvar sıkıntısını gidermek için Azerbaycan tiyatrosuna uzun yıllar onurla hizmet vermiştir. Ancak adı geçen bu yazarların şiir ve düzyazıdan tiyatro yaşamına geçiş yaptığı dönem, şüphesiz Adil İsgandarov’un ve daha sonra Mehdi Mammadov ve Tofig Kazımov’un yaratıcılığg ile iş birliği içinde gerçekleşmiştir. Böylelikle Adil İsgandarov, yazarları tiyatronun çalışmalarına dâhil etmiş, onlara tiyatroyu sevdirmeyi başarmış ve onlar bu sayede tiyatronun adamı olabilmişlerdir.

Kısa sürede Azerbaycan milli dramasının yeni örnekleri ortaya çıkmıştır. Bu örnekler sadece gösteri sanatlarının ifade araçlarını genişletmekle kalmamış, aynı zamanda yeni nesil oyunculuk güçleri ve aktörlerin oluşum sürecini de hızlandırmıştır. Bir yandan milli yönetmenin sanatının üslup özellikleri için elverişli koşullar, ifade imkânları varken, diğer yandan da bireysel oyuncuların sanatsal potansiyelini artırmak için elverişli koşullar oluşturulmuştur. Elbette bu, milli tiyatroyu temsil eden eserlerin tiyatronun repertuvarında ve repertuvarın inşasında kilit rol oynadığı anlamına gelmiyordu. Uzun yıllar 
boyunca, dünya ve Avrupa klasiklerinden çevrilen eserlerin, Rus ve diğer halkların dramaturjisinin yanı sıra, milli klasiklerin ve modern yazarların eserleri de sahnede yer almış ve bu denge estetik açıdan değil, politik bir bakış açısıyla düzenlenmiştir.

Adil İsgandarov'un yönetmenlik sanatının özelliklerinden bahsederken, her şeyden önce o dönem Azerbaycan tiyatrosunun görkemli unsurları dikkat çekicidir. Bu her şeyde kendini göstermiş̧ir. Ölçeğin genişliği, anlatım tarzının büyük anlamda ortaya çıkması, tasarımın mekânsal tertibatı, sahnenin ihtişamı dahil her şey o dönemin tiyatro performanslarının özellikleri arasında yer almıştır. Ayrıca bu özellikler Adil İsgandarov’un çalışmalarında daha belirgin bir yer tutmuştur. İsrafilov’a göre (2001, s. 80), “A. İsgandarov'un oyunlarının tertibatında kilit rol oynayan muhteşem sahne dekoru, doğal olarak aktörün parlak ifadesiyle canlandırılan büyük ölçekli ve renkli sahne düzenlemeleri ile karakterize ediliyordu. Bu tasarımın kıyafeti ve donanımı, ışıklandırma prensipleri ve hatta perdeyi açıp kapama ritmi çok hassas bir şekilde işlenmiştir”.

A. İsgandarov, hayal gücünden oyunun yorumlama koşullarını, sanatsal her detayı, en sıradan vuruşlara kadar sahneye aktardığında özel bir tutarlılık göstermiştir. Prof. R. Bədəlov, yönetmenin sanat yaşamına en uygun sanatçılar arasında ressam Nusret Fatullayev ve oyuncu Alasgar Alakbarov'dan bahsetmektedir. Eleştirmen, Nusrat Fatullayev'in eşsiz bir bakış açısıyla sahnede 〈hayatì bir illüzyon, mimari planlar oluşturduğunu ve özenle işlenmiş giysiler yaptığını ifade etmektedir (1993, s. 25).

Çok katlı bir sarayı tasvir eden sahne, dört veya beş saatten fazla süren performanslar, sadece tiyatro eleştirmenleri tarafından değil o dönemin tiyatro seyircileri tarafından da hatırlanan kırk beş dakikadan fazla aralar içeren oyunlara rastlanmıştır. Bugünün şartlarında ele alındığında tuhaf karşıllanabilecek ağır ve büyük süslemeler ile bir dizi diğer süslemeler ana oyun alanının dışında bırakılmış ve yeterince geliştirilmemiştir. Bu gerçeği yorumlayan Prof. R. Bədəlov'un (1993, s. 28) yazdığı gibi, “Aslında, sanatçı N. Fatullayev tarafindan tasarlanan bu mekân koşullu bırakılmış, muhtemelen oyuncunun sahnede yaşaması amaçlanmamış ve bazen bir süs şeklinde kalmıştır”.

Yukarıdaki ifadenin doğru kısmına ek olarak tartışmalı kısmı da bulunmaktadır. A. İsgandarov'un sanatsallığını incelerken, çok az rastlantı olması da dikkat çekicidir. Uzun tartışmaların, müzakerelerin, varsayımların ve tereddütlerin sonucu olan tasarım çalı̧̧masının "oyuncunun sahnede yaşaması için tasarlanmış" (Kazımov, 1990, s. 12) olması ikna edici görünmemektedir. Tiyatrodaki pratik yaratıcı yaşamından, yönetmenlik sana- 
tının deneyiminden yola çıkılarak, İsgandarov'un oyun üzerindeki çalışmasına tasarım çözümleri ve rol dağılımı ile başladığı anlaşılmaktadır. Sanat konularında titizliği ve tavizsiz doğası ile ayırt edilen A. İsgandarov sadece güzel değil, aynı zamanda süslü bir sahne yaratma eğiliminde olanlara karşı sert önlemler almaktadır. Bu durumda hiçbir şeyi unutması veya dikkat etmemesi imkânsız görünmektedir. Oyundaki "her adımı, oyuncuların her bakışını görüntünün gerçek durumuna, oyunun içeriğine ve dramatik olaya tabi kılmay1" zorunlu bir estetik gereklilik haline getiren A. İsgandarov, görkemli dekorları ve tasarım araçlarına da amacı doğrultusunda gereken önemi vermiştir (Kazımov, 1990, s. 14).

Rəhimli’ye göre (1996, s. 42), Azerbaycan tiyatrosunda dekor tasarımı özellikleri belirlenmiştir:

"Bir oyunun tasarımını, fotoğrafçının bir arka plan yaratma girişimiyle bir tutmanın yanlış olacağı bilinen bir gerçektir. Çünkü dekor dâhil tasarım, oyuncunun oyunu için dekoratif bir iç mekân değil, her şeyden önce oyunun sanatsal imgesi ve güncel olaylarının havasını yansıtmaktadır. Tasarımın merkezi bir konuma sahip olduğu ve ağırlık merkezi olan performansın ilk estetik etkisi bu işlevdedir."

Həsənov (1940, s. 29), dekor tasarımının etkisine dair izlenimlerini şu şekilde aktarmıştır:

"Perde açılır açılmaz, izleyicinin ilgisini çeken ilk sahne ve adeta bir sanat olayı tasarımla başlar ve ilk izlenim sistematik olarak tasarımın çağrıştırdığı anlamlarla algılanır. Çeşitli tiyatro sahnelerinde izleyicilerin ilk alkışlarının genellikle tasarım kısmına düştüğü unutulmamalıdır. Bir başka ilgi çekici gerçek de bazı performansların tasarımıyla ilgili özel makalelerin bir zamanlar ulusal basınımızda yayınlanmış olmasıdır."

A. İsgandarov'un sahneyi yeterince kullanmadığını, ancak her halükârda tamamen boş bırakmadığını belirtmek gerekir. İlginçtir ki, A. İsgandarov Rəhimli ve Həsənov'un değindiklerine uygun sahnelemeler gerçekleştirirken, kendisinden sonra Azerbaycan tiyatrosunda görev yapan M. Mammadov, T. Kazımov gibi yönetmenlerin tavırlarında benzer özene rastlanmamıştır.

İsrafilov'a göre (2001, 81), söz konusu durumun neredeyse estetik bir vurgu olduğu ortaya çıkmıştır. Eğer bu yaklaşım sonraki yıllardaki uygulamalarda kendini kanıtlayan ve 
sanat olayına getirilen bireysel bir üslup gerçeğiyse, o zaman A. İsgandarov, milli yönetmenlik sanatında bu tarzın yaratıcısı olarak düşünülmelidir.

A. İsgandarov'un sanatsal yaşamı ve sanatsal faaliyeti üzerine Bədərbəyli’nin (1967, s. 51), yaptığ1 araştırmalar sonucunda, yönetmenin oyuncularından kendini ifade etme araçlarını geliştirmesini talep ettiği görülmüştür. Fakat bazı oyuncuların, ne kadar uğraşırlarsa uğraşsınlar yönetmenin oyuncularla aynı seviyede ve aynı şevkle çalışamayacağını düşündükleri doğrudur.

Oyuncu ile oditoryum arasındaki yeni iletişim ilkeleri tanımlanmalıydı. Bu sorunu çözmek için A. İsgandarov sinema unsurunu uygulamaya çalışmış, sinemanın genel, orta ve büyük ölçekli etkilerini sahnede denemeye karar vermiştir. Bu girişimin sonucu ona göre çoğunlukla başarılı olmuştur. Bu durumun başka bir yönü daha bulunmaktadır; bu da dekorasyonları kullanmama sorunudur. Ancak tüm bunlarda önemli olan estetik gerçek ve sanatın gerçek zorluğu, romantik betimleyici şiirlerin, gösteri sanatlarında egemen bir konum kazanan ihtişamın sanatsal estetik yasalarını hesaba katmak zorunda kalmasıdır. Bunlar bir yandan Adil İsgandarov'un sevdiği ve tercih ettiği tarz, bir yandan da zamanın estetik gerekleridir. Çünkü, o zamanki SSCB'deki tiyatroların çoğunda, büyük fikirlerin çatışmasıyla seçilen eserlerin sahnelendiği görülmektedir. Yani devletin devasa inşaat işleri, devasa programlar yapma arzusu kural olarak sanat eserlerine de uygulanmıştır. Bu yaklaşım sanat eserlerine, özellikle de zamanın tiyatro sanatına açıkça yansımıştır.

A. İsgandarov'un sahnede ortaya koyduğu eserlerin yazarları arasında çeşitlilik görülmüş, bu durum tiyatro otoriteleri tarafından alışıldık bir eylem olarak değerlendirilmiştir. Ancak A. İsgandarov'un farklı yazarların farklı konulardaki çalışmalarını benzer estetik üslupla hazırlaması ise garip durmaktadır (İsrafilov, 1999, s. 82).

A. İsgandarov tiyatronun hem ideolojik açıdan bir temsilcisi hem de yönetmeniydi. Oysa bu durum yönetmenin konseptinin işlevsel doğasından ve faaliyet alanından çok farklı durmaktaydı. Genel sanat yönetmeni, ideolojik ve sanatsal kapasiteye sahip, estetik açıdan hoş bir teatral modeli ortaya çıkarmak için mesai harcarken, idari müdür, kamusal ihtiyaçları ve bireysel çıkarları karşılamak için özenle çalışma sergileyen bir mesaide bulunmak durumundaydi.

Son olarak belirtmek gerekir ki, A. İsgandarov'un yönetmenlik metodu, Azerbaycan tiyatro sanatı yaratıcılığının orta döneminde kendini gösterir. Ancak bu metot halihazırda mü- 
kemmel bir yönetmenlik becerisi sahnelemekten uzaktır. Buna rağmen tiyatronun iç süreçlerindeki işleyişin nispeten acısız ve kayıpsız geçişinin yanı sıra kamusal yaşamda görülen canlanmanın A. İsgandarov'un müdahaleleri sayesinde mümkün olduğu unutulmamalıdır. Burada her şeyden önce A. İsgandarov'un kamusal imajının işe yaradığı görülmüştür.

Daha sonra tiyatro kültüründe öyle bir resim ortaya çıkmıştır ki, yönetmenlik tarihi hakkında düşünmek, genel olarak tiyatro tarihini düşünmekle eşdeğer bir görüntüyü ortaya koymuştur. Bu, şüphesiz yönetmen Adil İsgandarov'un başarısıdır.

\section{Sonuç}

Adil İsgandarov, Azerbaycan Milli Drama Tiyatrosu'nda güçlü bir ekip oluşturarak ve çeşitli yenilikleri getirerek kendi yönetmenlik okulunu kurmuştur.

Adil İsgandarov, Azerbaycan Milli Drama Tiyatrosu'nda oyuncunun sahnede sufleye muhtaç olmasına son vermiştir. İsgandarov, her oyuncunun ve topluluğun yaratıcı gücünü sahneye bir bütün olarak tanıtmıştır. Rus tiyatrosunun, büyük ölçüde Batı Avrupa tiyatrosunun köklerine dayanan sanat anlayışına güçlü bir milli ruh aşılamıştır. Tiyatro estetiğinin ve halk oyun performanslarının organik birliğini yaratmıştır.

Başta Rusya olmak üzere dünyada var olan ilerici oyunculuk teorilerinin bir araya gelmesinden türetilen bir sistem yaratarak, Akademik Tiyatrodaki sahne ustalarının rolüne cesurca uygulamıştır. Adil İsgandarov, tiyatronun canlı faaliyet organizmasında (provalarda, oyunun gidişatında, turne gezilerinde vb.) sıkı bir disiplin geliştirmiştir.

Tiyatro çevresinde Samad Vurgun, Mehdi Hüseyin, Sabit Rahman, Anvar Mammadkhanl1, İlyas Efendiyev gibi güçlü yazarlardan oluşan bir sanatçı ordusunu bir araya getirmiştir. 'Adil İsgandarov Tiyatrosu' ifadesinin, fayda sağlayan temellere dayanan canlı bir tiyatro kavramı olarak yerleşmesini sağlamıştır.

Adil İsgandarov bu okulun güçlü oyuncu kadrosunu eğiterek yetiştirmiştir. Örneğin: Alasgar Alakbarov, Hokuma Gurbanova, Rza Afganlı, Leyla Badirbeyli, Malik Dadaşov, Ajdar Sultanov, Hasanağa Salayev.

Genel olarak Azerbaycan'ın tüm sahne sanatlarının bir örneği olan Milli Drama Tiyatrosu'nu Akademik seviyeye yükseltmiştir. Hem ahlaki hem de resmi olarak "Akademi” adını tasdikleterek (16 Aralık 1959), ekibin ününü eski SSCB ülkeleri arasında duyurmuștur. 
Adil İsgandarov'un baş yönetmenliği döneminde, genç milli yönetmenlere ciddi sahnelemeler emanet edilmiş ve kademeli olarak güçlü bir yönetmen ekibi oluşturulmuştur. Şamsi Badalbeyli'ye, Mecid Zeynalov'a, Saftar Turabov'a, Aliheydar Alakbarov'a, Ağal1 Dadaşov'a, Eşref Guliyev'e bağımsız sahnelemeler emanet edilmiştir.

Adil İsgandarov Azerbaycan Milli Tiyatro tarihinde oyunu binden fazla kez sahnelenen tek yönetmendir. Bu "Vagif" isimli oyundur (bininci oyun 31 Mayıs 1977'de oynand1), "Ferhat ve Şirin" 450'den fazla kez, "Şanslılar” 350'den fazla kez seyirciyle buluşmuştur.

Azerbaycan Milli oyuncularının filmlerde daha çok oynamaları için ciddi idari ve yaratıcı çalışmalarda bulunmuştur.

Adil İsgandarov, dünyaca ünlü Azerbaycan klasik sanatçılarının ve kahramanlarının sahnede ve ekranda görüntülerinin canlandırılmasında ve Azerbaycan klasik eserlerinin gösterilmesinde etkili reformlar gerçekleştirdi.

O hem sahne çalışmalarını hem de insani niteliklerini ve potansiyellerini iyi tanıdığı oyuncularla çalıştı̆̆ için repertuvar oluştururken karmaşık karakteri oynayacak oyuncu bulma konusunda zorluk yaşamamıştır.

Adil İsgandarov'dan önce hiçbir yönetmen, grubun önde gelen oyuncuları için üç, beş ve hatta yedi yıllık bir çalışma içeren plan-program hazırlamamıştır. Hem Alasgar Alakbarov hem Rza Afganlı hem de Hokuma Gurbanova için zirveye giden sanatsal yaşamlarının temelini Adil İsgandarov atmıştır.

Hakem Değerlendirmesi: Dış bağımsız.

Çıkar Çatışması: Yazar çıkar çatışması bildirmemiştir.

Finansal Destek: Yazar bu çalışma için finansal destek almadığını beyan etmiştir.

Peer-review: Externally peer-reviewed.

Conflict of Interest: The author has no conflict of interest to declare.

Grant Support: The author declared that this study has received no financial support.

\section{Kaynakça/References}

Olizadə, M. (1998). Teatr: Seyr və sehr. Elm jurnal, (1), 19-31.

Bədəlov, R. (1993). İncəsənətimizi qoruyaq. Azadlıq qazeti jurnall, 27(2), 25-77.

Bədərbəyli, L. (1967). Səhnəmizi düşünərkən. Odəbiyyat və Íncəsənət jurnall, 17(1), 51-59.

Həsənov, O. (1940). "Xanlar” pyesinin bədii tərtibat1. Odəbiyyat qazeti jurnall, 5(1), 27-36.

İsgandarov, A. (1958). Yaradıcılıq əməkdaşlığı. Әdəbiyyat və İncəsənət jurnalı, 8(2), 4-16. 
İsgandarov, A. (1972). Kinomuzun gələcəyinə inam. Әdəbiyyat və İncəsənət jurnall, 22(1), 7-29.

İsrafilov, İ. (2001). Azərbaycan Milli Rejissor Sənətinin Poetikası. Bakı: “İsmayıl” Nəşriyyat Poliqrafiya Müəssisəsi.

Kazımov, A. (1990). Görkəmli rejissor. Odədiyyat va İncasənət jurnall, 40(1), 11-23.

Monastyrysky, П. (1985). Главный режсиссор. Куйбышев. Москва: Куйбышевское книжное издательство.

Popov, А. (1972). Спектакль и режиссер. Москва: ВТО.

Qədri, F. (1983). Həyatımdan səhifələr. "Səhnədən keçən yollar” kitabında. Yazıçı jurnalı, 12(2), 117-129.

Rəhimli, İ. (1996). Azərbaycan milli teatrının poetikasl, sənətşünaslıq doktoru dissertasiyası. Bakı: Azərbaycan EAnın fundamental kitabxanası.

Talıbov, A. (1992). Min maska və bir mən. Yeni yol jurnalı, 1(2), 9-22. 